\title{
Welding of Aluminum Using a Pulsed Nd:YAG Laser
}

\author{
M. Nerádová, P. Kovačócy
}

\begin{abstract}
This paper deals with pulsed laser welding of aluminum using an Nd:YAG laser with wavelength $1.06 \mu$ m. Technically pure aluminum (95.50 wt. \%) was used as the welded material. Eighteen welds (penetration passes) were fabricated in the experiment. Optical microscopy was used to assess the influence of changes in the parameters of the pulsed laser on the quality and geometry of the penetration passes of aluminum and on the hardness measurement through the interface of the welds. The results show that the geometry of the penetration passes was influenced above all by the position of the beam focus.
\end{abstract}

Keywords: welding parameters, laser welding, aluminum, weldability of aluminum.

\section{Introduction}

Laser beams can be applied in a versatile manner in a wide range of technical and non-technical fields. In laser welding of materials, various types of laser devices with various power ranges are used. The automotive industry is one of many areas where laser welding of aluminum is utilized [1]. Aluminum and its alloys are characterized by low density, relatively high strength and high corrosion resistance [2, 3]. They are used as structural materials in various industrial fields.

Welding of aluminum and its alloys has its specific features. Aluminum oxidizes strongly above its melting point. The oxidic layer has a high melting point, and it does not melt in the welding process [4]. This layer has a strong ability to absorb gases and vapors, which then get into the weld metal. Oxidic particle layers may lead to the presence of oxidic inclusions in the weld metal, which deteriorates the characteristics of the welded joints [5].

When welding aluminum, it is necessary to use a higher intensity laser beam on the surface of the workpiece, due to the high reflectivity of aluminum [4]. Given the high reflectivity of the radiation from the surface of aluminum, it is preferable to use just an Nd: YAG laser. Depending on the configuration and the geometry of the welds, additional materials are sometimes used for aluminum welding. When welding aluminum and its alloys, pores often form in the weld metal. Source of these pores is hydrogen. Hydrogen has at melting temperature of aluminum relatively high solubility [5].

The high thermal conductivity and the high coefficient of expansion of aluminum give rise to major distortions in comparison with steel. The use of highly concentrated laser beam welding provides the preconditions for success in addressing these problems. In order to obtain high-quality welded joints, it is particularly necessary to prepare the surface prior to laser welding. The oxidic layer along the length of the surface has to be removed. This surface preparation minimizes the formation of defects in welding and the presence of pores and oxidic inclusions in the weld metal [2].

When welding aluminum alloys, it is essential to protect the gas bath melt from oxidation. The use of helium as the protective gas enables maximum depth for translating a high quality weld metal.

The basis for achieving high-quality welded joints is the correct choice of the laser welding parameters. The microstructure of the weld metal joints made by the laser beam and the optimal welding parameters are significantly different from the microstructure of weld joints made with the use of metal arc welding. The weld metal has a fine dispersion structure without the presence of low-eutectic, while the dendrite dimensions are significantly smaller than in arc welding. The structural changes in the heat-affected area of laser welding take place in a volume 5 to 6 times smaller than in the case of arc welding. The grain in this area increases minimally. This structure is advantageous in terms of mechanical properties and good resistance to hot cracks [1].

\section{Experimental materials}

Technically pure aluminium was used as the experimental material. The dimensions of the test samples were $76 \times 30 \times 1 \mathrm{~mm}$. The chemical composition of Al $99.50 \%$ is shown in table 1 . 
Table 1: Chemical composition Al 99.50 wt. \%

\begin{tabular}{|c|c|c|c|c|c|c|}
\hline material & \multicolumn{6}{|c|}{ Chemical composition [wt.\%] } \\
\hline Al min & $\mathbf{F e}$ & $\mathrm{Si}$ & Zn & $\mathbf{C u}$ & $\mathbf{T i}$ & Others \\
\hline 99.50 & $\max .0 .40$ & $\max .0 .30$ & $\max .0 .07$ & max. 0.05 & $\max .0 .05$ & $\max .0 .03$ \\
\hline \multicolumn{7}{|c|}{ Mechanical characteristics } \\
\hline \multicolumn{2}{|c|}{$\begin{array}{c}\text { Rm (MPa) } \\
60-100\end{array}$} & \multicolumn{3}{|c|}{$\begin{array}{c}\text { Ductility } A_{5}[\%] \\
\text { min. } 10-20\end{array}$} & \multicolumn{2}{|c|}{$\begin{array}{c}\text { Modulus of elasticity } E \\
{[\text { GPa] inf. } 71}\end{array}$} \\
\hline
\end{tabular}

Table 2: Welding parameters

\begin{tabular}{|c|c|c|c|c|}
\hline Sample & $f(\mathrm{~mm})^{*}$ & $\tau(\mathrm{ms})^{*}$ & $U(\mathrm{~V})^{*}$ & $E_{1}(\mathrm{~J})^{*}$ \\
\hline 1.1 & 5.5 & 20 & 400 & 69.8 \\
\hline 1.2 & 5.25 & 20 & 400 & 70.1 \\
\hline 1.3 & 5.0 & 20 & 400 & 70.2 \\
\hline 1.4 & 4.75 & 20 & 400 & 69.9 \\
\hline 1.5 & 4.5 & 20 & 400 & 70.0 \\
\hline 1.6 & 4.25 & 20 & 400 & 69.8 \\
\hline 1.7 & 4.0 & 20 & 400 & 70.3 \\
\hline 1.8 & 3.75 & 20 & 400 & 70.0 \\
\hline 1.9 & 3.5 & 20 & 400 & 69.1 \\
\hline 1.10 & 3.25 & 20 & 400 & 70.1 \\
\hline 1.11 & 3.0 & 20 & 400 & 70.1 \\
\hline 1.12 & 2.75 & 20 & 400 & 69.9 \\
\hline 1.13 & 2.5 & 20 & 400 & 70.1 \\
\hline 1.14 & 2.25 & 20 & 400 & 72.8 \\
\hline 1.15 & 2.0 & 20 & 400 & 74.2 \\
\hline 2.1 & 2.75 & 20 & 400 & 69.8 \\
\hline 2.2 & 2.75 & 20 & 375 & 63 \\
\hline 2.3 & 2.75 & 20 & 350 & 53.1 \\
\hline
\end{tabular}

$* f(\mathrm{~mm})$ - focal length, $\tau(\mathrm{ms})$ - pulse duration, $U(\mathrm{~V})$ - pump power, $E_{1}(\mathrm{~J})$ - pulse energy

\subsection{Procedure and parameters for welding}

The experiment was executed at the International Laser Centre in Bratislava. The experimental work was performed on a W50 Laser Welder, produced by Solar Laser Systems, with wavelength $1.06 \mu \mathrm{m}$ and maximum output power 74.2 J. During the experiments, 18 penetration passes were carried out, in which we observed the impacts of the focus location, the intensity of performance and also the impact of the energy pulse values on the geometry and integrity of the welds. Laser welding was performed in a protective atmosphere of argon with $5 \mathrm{l} / \mathrm{min}$. flow. The welding parameters are shown in table 2 .

\subsection{Assessment of penetration welds}

Optical microscopy was used for assessing the penetration welds and for measuring the hardness (HV) through the interface of the welds. Figs. 1 to 4 document the macrostructures of penetration weld 1.2-1.5. It follows from observing the structures that in the case of samples 1.1-1.4 the material was not fully penetrated due to low power density.

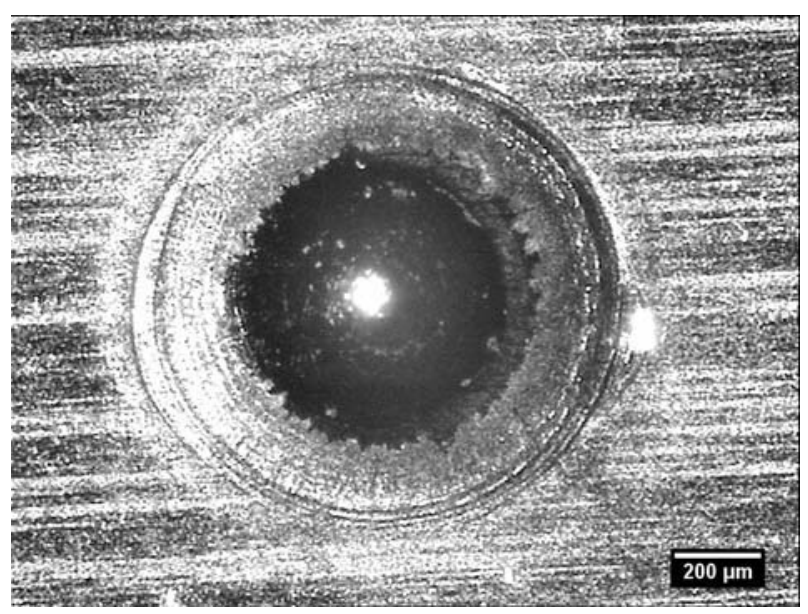

Fig. 1: Surface of penetration pass 1.5

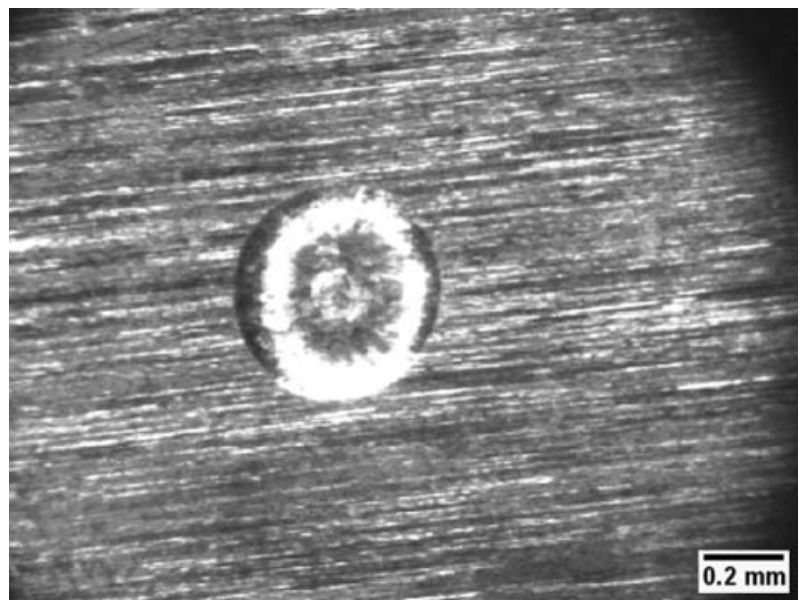

Fig. 2: Root of penetration pass 1.5 


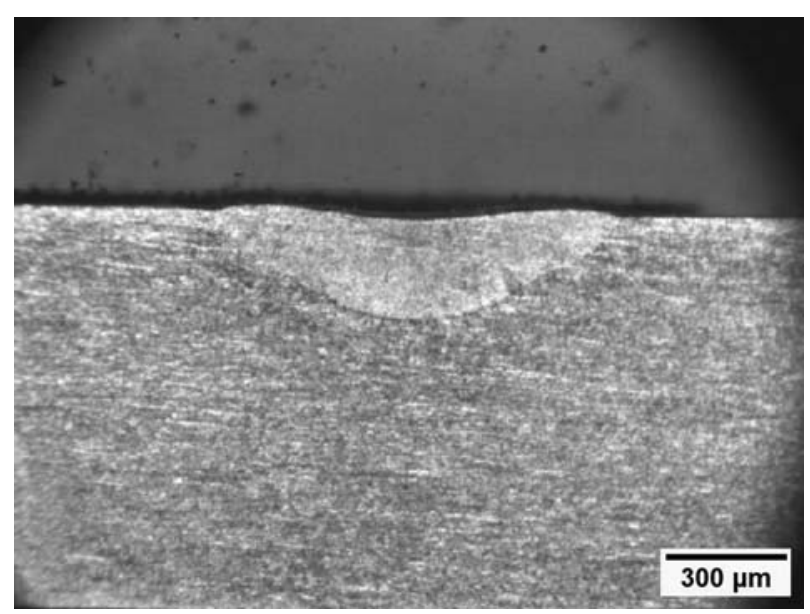

Fig. 3: Penetration pass 1.2

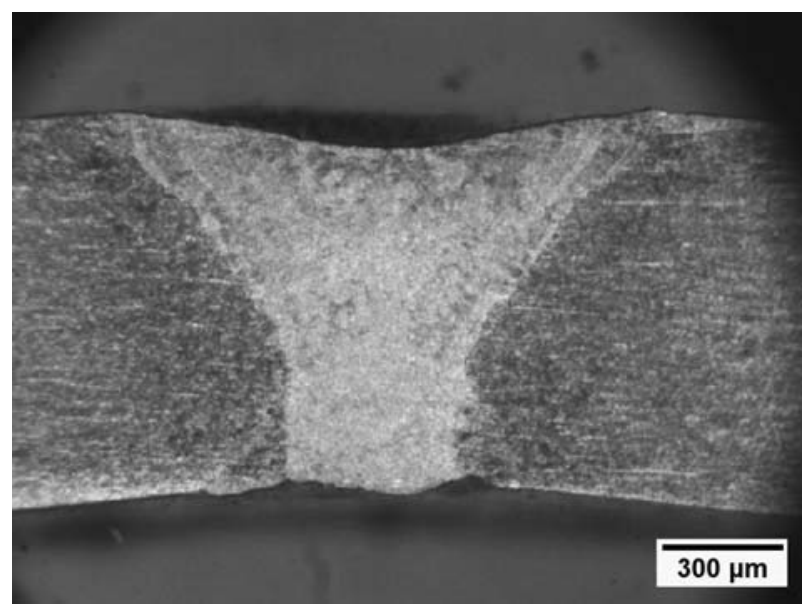

Fig. 4: Penetration pass 1.5

The surface and the root of penetration pass 1.5 are distinguished by roundness without a split. The position of the focus in relation to the surface of the material has caused the whole width of the material to be penetrated. A slight depression can be seen on the surface of the material, Fig. 4. The weld metal does not show any non-integrities or defects. The width of the surface of the penetration pass is $1.336 \mathrm{~mm}$ and the width of the root of the penetration pass is $0.872 \mathrm{~mm}$. Figs. 3 and 4 show differences in the character of the penetration. In Fig. 3, the material was not liquidized - this is known as conductional mode welding. In this mode, a thin surface layer of material is melted down and then is material heated due to the thermal conductivity. In Fig. 4, the parameters are used to produce a sufficient keyhole to enable deeper penetration of the laser beam into the material.

Fig. 5 documents the microstructure of the transition (the heat-affected zone - boundary melting down — weld metal) on penetration weld 1.5. Fig. 6 shows the microstructure of the welding metal.

Grain (subgrain) boundaries were observed in the weld metal with oxides distribution inside the grains.

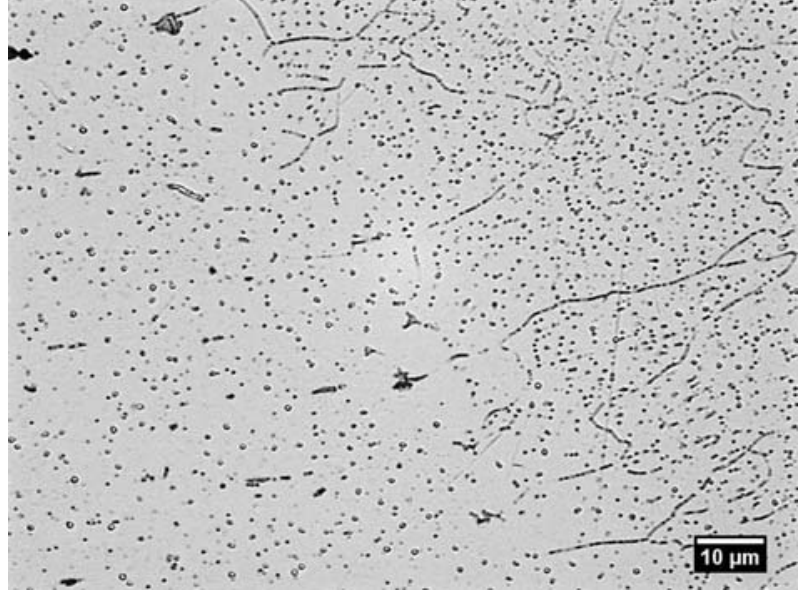

Fig. 5: Microstructure the heat-affected zone (Al $99.50 \%)$

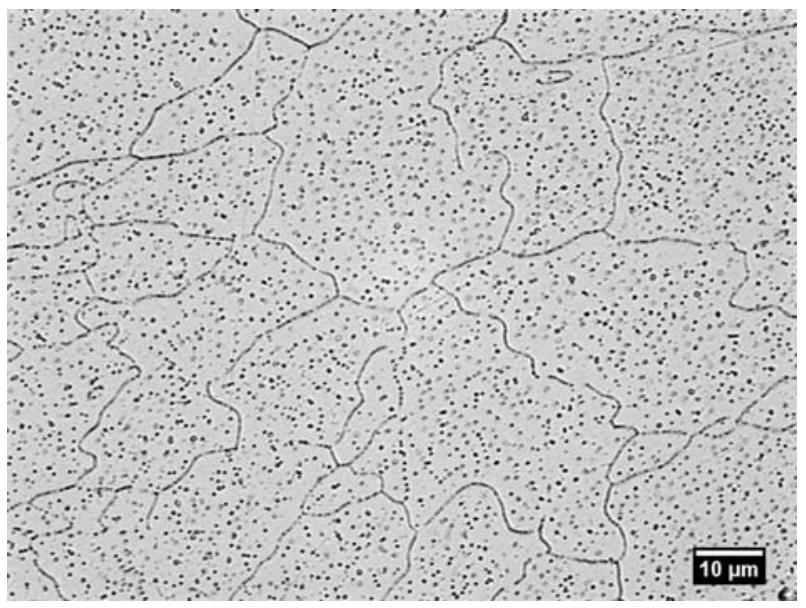

Fig. 6: Microstructure weld metal (Al $99.50 \%)$

No non-integrities were present. A smelting boundary can be observed between the heat-affected zone and the weld metal, and there is a smooth transition between them. The orientation of the dendrites can be observed in the weld metal.

Vickers microhardness tests were conducted on samples 1.5, 1.9 and 2.1. Figs. 7 to 9 show the effect of some parameters on the geometry of the penetrations.

Ten measurements were made on each sample. Fig. 10 shows that the highest microhardness values were for sample 1.9. This may be due to the smaller volume of the smelted material, quicker cooling of the material, and the formation of a finer structure.

In welds $1.5,1.9,2.1$ the highest microhardness is in the parent material. This may be because the material has been cold-rolled. The hardness drops in the heat-affected zone due to thermal processing, and on the smelting boundary and in the welding metal the hardness starts to rise. The welding metal is characterized by the pouring structure. The slight growth in the hardness of the welding metal may be due to softening of the structure. 


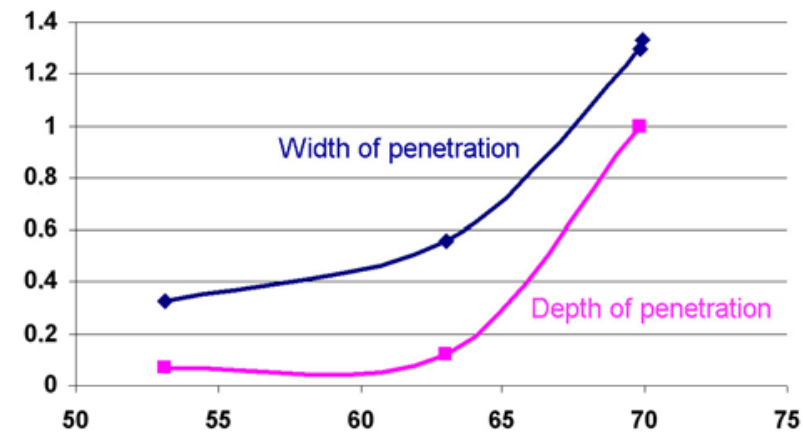

Fig. 7: Effect of pulse energy on the geometry of the penetration passes

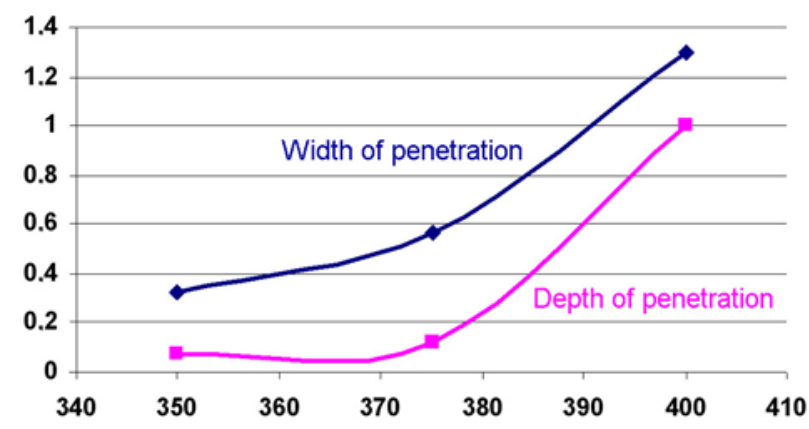

Fig. 8: Dependence of the width and depth of penetration on the excitation voltage

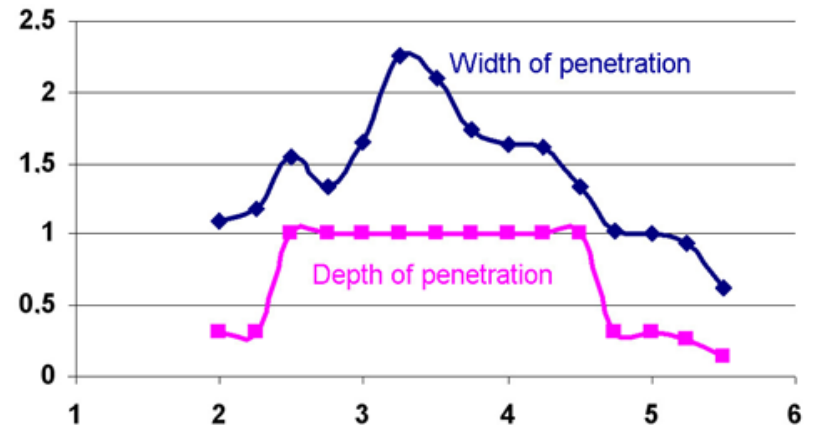

Fig. 9: Influence of the focal length on the geometry of the penetration passes

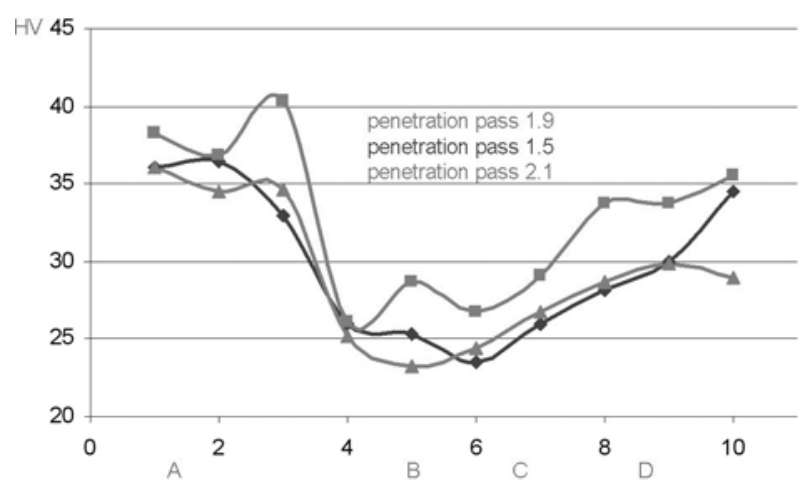

Fig. 10: Graphic illustration of the course of microhardness on samples $1.5,1.9,2.1 A$ - parent material, $B-$ heat-affected zone, $C$ - boundary of smelting, $D$ - weld metal

\section{Conclusion}

Based on the results obtained in the experiment it can be stated, that the values of the standoff distance being between $0-2 \mathrm{~mm}$ and between $4.75-5.5 \mathrm{~mm}$ are characterized by low penetration weld form factor (conductional welding system), which is more suitable for surface treatment of materials. A total of 10 samples were used to recast the whole thickness of the material. The standoff distance in these cases varied in the range from $2.5-4.5 \mathrm{~mm}$. Excitation voltage of $400 \mathrm{~V}$ was used for the production of penetrations. Because of the possibility of assessing the impact of voltage-inspiring geometry, penetration welding was carried out at voltages $350 \mathrm{~V}$ and $375 \mathrm{~V}$. Based on the measured dimensions influences of voltage energy, pulse duration and standoff distance on the weld geometry were evaluated. Based on the results of macro and microstructural analysis, it can be considered, that the most suitable parameters were used for welding the sample no. 1.5. The greatest microhardness values were measured in the base material. In the thermally influenced area a decrease in hardness was observed.

\section{Acknowledgement}

The paper was prepared with support from the VEGA project, no. 1/0842/09.

\section{References}

[1] Turňa, M., Kovačócy, P.: Zváranie laserovým lúčom. Bratislava, STU, 2003.

ISBN 80-227-1921-8.

[2] Accessible on internet: http://www.world-aluminium.org/?pg $=107$

[3] Accessible on internet: http://www.chemicool.com/elements/ aluminum.html

[4] Accessible on internet: http://www.keytometals.com/Article12.htm

[5] Ghaini, F. M. et al.: The Relation Between Liquation and Solidification Cracks in Pulsed Laser Welding of 2024 Aluminium Alloy. Accessible on internet: http://www.sciencedirect.com

Ing. Martina Nerádová

Doc. Dr. Ing. Pavel Kovačócy

Phone: +421335 521007

Slovak University of Technology in Bratislava Faculty of Materials Science and Technology in Trnava

Institute of Production Technologies

Bottova 23, 91724 Trnava, Slovak Republic 